\title{
ADIPOSE-DERIVED STEM CELLS IN TISSUE ENGINEERING: LABORATORY TO BEDSIDE
}

\author{
Halim $A S^{1}$, Mohaini $M^{1}$, Chin Keong $L^{2}$ \\ 1 Reconstructive Sciences Unit, School of Medical Sciences, Universiti Sains Malaysia, Kelantan \\ 2 Department of Research and Development, Wipro-Unza (Malaysia) Sdn Bhd, Subang Jaya, Selangor
}

\section{Correspondence:}

Ahmad Sukari Halim

Dean Office, School of Medical Sciences, Universiti Sains Malaysia, 16150 Kubang Kerian, Kelantan, Malaysia.

E-mail: ashalim@kb.usm.my

\begin{abstract}
Human adipose tissue has been recognized as an alternative source of adult stem cells. The abundance and ease of harvest of adipose tissue has made it suitable for use in regenerative medicine and tissue engineering. Adipose-derived stem cells isolated from human adipose tissue are able to differentiate into several mesenchymal lineages and secrete growth factors that exhibit therapeutic potential. Protein profiles have been established using various isolation methods, which has expanded researchers' understanding of adipose-derived stem cells in clinical applications. This review highlights the properties, isolation methods, immunophenotype and clinical applications of adipose-derived stem cells.
\end{abstract}

Keywords: adipose-derived stem cells, immunophenotyping, isolation methods, clinical applications

\section{Introduction}

Advances in the fields of biomedical engineering, biochemistry, genetics, material science, cell biology and molecular biology have given rise to the remarkable new cross-disciplinary field of tissue engineering. Large-scale human and animal cell cultures that include skin, cartilage, muscle, bone, endothelial and stem cells have been studied and clinically applied to replace damaged tissues or organs in humans. This new branch of modern medicine has been termed regenerative medicine. Regenerative medicine combines several factors, including cells, growth factors and biomaterials. Strategies include cell therapy, biomaterials alone and combinations of cells and biomaterials (1). When implanted in the body as temporary structures, naturally derived or synthetic biomaterials can provide templates that guide tissue formation while the scaffold is gradually biodegraded. Stem cells for regenerative medicine should have the following criteria: they (a) are abundantly present, (b) can be harvested using minimally invasive procedures, (c) are able to reproducibly differentiate into multiple cell lineages, (d) can be safely and effectively transplanted to either an autologous or allogeneic host, and (e) can be manufactured in accordance with current Good Manufacturing Practice (GMP) guidelines (2).

Generally, stem cells are unspecialized cells that are able to multiply themselves or become specialized types of cells.
Stem cells can be divided into several classes according to potency; namely, totipotent stem cells can build an entire organism, and pluripotent stem cells can become all tissue types except for extraembryonic tissues such as placenta and amnion. Multipotent stem cells are able to develop into more than one cell type in the body. Cells that can differentiate into only one cell type are known as precursor cells or progenitor cells (3). Bone marrow is a recognized source of mesenchymal stem cells for regenerative medicine. Mesenchymal stem cells (MSC) from bone marrow are aspirated from patients using painful procedures and with relatively lower yields of cells than MSCs from adipose tissue (4).

Embryonic stem cells (ESCs) are derived from the inner cell mass of the blastocyst during embryogenesis. ESCs were first isolated from mouse embryos in 1980 and then later from humans in 1998 (5). Despite their pluripotency, humanity and ethics concerns relating to the destruction of embryos to obtain ESCs have been raised by various religious and research institutions worldwide. Differentiated cells reprogrammed to stem cells, called induced pluripotent stem (iPS) cells, are another interesting source of stem cells. Typically, iPS cells are produced by transfecting differentiated or adult cells with stem cellassociated genes. Thus, their properties are remarkably similar to ESCs (6). 
Adult stem cells can be isolated from a mature organ such as bone marrow, adipose tissue, dermis, trabecular bone, periosteum, pericytes, blood and synovial membrane (7). These stem cells usually replicate to replace the dead cells of their origin organ. Thus, their multi-potency to differentiate into other lineages can be employed in stem cell-based therapy. In 2006, the Mesenchymal and Tissue Stem Cell Committee of the International Society for Cellular Therapy provided several guidelines to define human mesenchymal stromal cells, such as adherence to plastic culture flasks; expression of specific antigens/ markers such as CD105, CD73 and CD90; and multipotent in vitro multi-lineage differentiation into osteoblasts, adipocytes and chondroblasts (8).

\section{Adipose tissue and adipose-derived stem cells}

Adipose tissue modulates energy homeostasis and secretes lipids and proteins, as well as peptides such as hormones, adipokines and cytokines (9). The majority of adipose tissue in mammals can be found in the subcutaneous and intra-abdominal areas (10). Subcutaneous fat is the fat present below the skin, and intra-abdominal fat is omental, mesenteric and perirenal. There are two types of adipose tissue: white adipose tissue (WAT) and brown adipose tissue (BAT). White adipose tissue is predominantly present in adults, while brown adipose tissue is present in newborns. The largest deposits of WAT are in the subcutaneous and visceral areas (11). Based on structural and ultra-structural features, three types of subcutaneous WAT have emerged: deposit WAT (dWAT), structural WAT (sWAT) and fibrous WAT (fWAT) (12).

Adipose tissue originates from the mesodermal layer during embryogenesis. Adipose tissue is vascularized by a capillary network of blood vessels during development. Mature adipocytes are filled with a single lipid droplet interlarded with stroma, which is composed of fibroblasts, blood vessels, leukocytes, macrophages and preadipocytes (lacking the lipid droplet) (13). Approximately $10 \%$ of fat cells are renewed each year, irrespective of body mass index and at all adult ages (14). As adipocytes are a terminally differentiated cell, their replacement with new adipocytes to compensate for lost adipocytes originates from a population of progenitor cells (pre-adipocytes) that are present in the stromal fraction of the adipose tissue $(15,16)$.

Adipose tissue progenitor cells were initially thought to only differentiate into adipocytes. However, these cells have gained greater attention through recent research work showing that cells isolated from lipoaspirate have multipotential ability in vitro to differentiate outside of the adipogenic lineage, including differentiation to chondrogenic, myogenic, and osteogenic cells via the use of specific growth medium induction (17). Therefore, adipose tissue harvested with minimal pain and great availability from surgical operations presents an alternative and promising source of stem cells for use in regenerative medicine. Many terms have been used in the literature to refer to cells isolated from adipose tissue, including adipose derived stem/stromal cells (ASCs), adipose-derived adult stem (ADAS) cells, adipose-derived adult stromal cells, adipose-derived stromal cells (ADSC), adipose stromal cells (ASC), adipose mesenchymal stem cells (AdMSCs), lipoblasts, pericytes, pre-adipocytes, and processed lipoaspirate (PLA) cells (18). To avoid confusion, the International Federation for Adipose Therapeutics and Science (IFATS) agreed to adopt the term "adipose-derived stem cells" (ASCs) to identify the isolated, plastic-adherent and multipotent cell population (18).

ASCs from adipose tissue have similar multipotency to that of MSCs from bone marrow (4). The population of ASCs may partly originated from pericytes and fibroblasts from surrounding adipose tissue environment (19). Pericytes are cells that line endothelial cells in capillaries and microvessels. Pericytic markers are expressed in ASCs cultures, implying that ASCs cultures may originate from pericytes resident in proximity to adipose tissue $(20,21)$. However, native ASCs do not express in situ pericytic markers, and ASCs can be found scattered in adipose tissue stromal (16).

The stromal vascular fraction (SVF) is the pellet obtained from collagenase digestion of adipose tissue. It can be composed of a heterogeneous cell population that includes pre-adipocytes, endothelial cells, fibroblasts, smooth muscle cells, pericytes, leukocytes and mast cells (22). However, cultured SVF displayed a fibroblast-like morphology and was maintained in vitro long term with a low level of senescence $(17,23)$.

There is increasing evidence that ASCs can be differentiated into mesodermal lineages, including adipogenic $(24,25)$, osteogenic $(24,26)$, chondrogenic $(27,28)$ and myogenic $(29,30)$ lineages in their respective growth medium. Moreover, ASCs can also be differentiated into nonmesodermal lineages, such as endothelial cells $(24,31)$, neuronal cells (32), epithelial cells $(33,34)$, pancreatic cells (35) and hepatocytes (36). Despite their multipotency, ASCs secrete several angiogenic and antiapoptotic factors such as vascular endothelial growth factor (VEGF) and hepatocyte growth factor (HGF), which may act synergistically for cardiovascular protection (37).

In vitro study has shown that ASCs promote dermal wound healing by increasing collagen synthesis, thus promoting fibroblast proliferation via the paracrine activity of ASCs secretory factors (38). In vivo study has shown that ASCs significantly reduce wound size in mice (38). Furthermore, factors secreted by ASCs produce a whitening effect by inhibiting melanin synthesis (39). ASC-conditioned medium has antioxidant properties because they protect human dermal fibroblasts from oxidative injury (40). Hair growth is stimulated upon treatment with the growth factors secreted by ASCs (41). In addition to wound healing, ASCs also have anti-ageing properties that act by stimulating collagen synthesis and angiogenesis (42).

In reconstructive surgery, skin flaps are used to repair defects caused by injuries and other causes. A lack 
of blood supply results in necrosis of the flap tissue. New blood vessel formation and the elongation of existing blood vessels are two mechanisms that assist revascularization. Newly formed blood vessels originating from the differentiation of ASCs into endothelial cells and the secretion of angiogenic factors improve the viability of the skin flap $(43,44)$.

\section{In vitro isolation and propagation technology for ASCs}

Primary cultures are created when cells grow out from an explants or attach to substrate after enzymatic or mechanical disaggregation (45). Primary cultures can be defined as a mixture of cells or highly purified cells isolated directly from organism. The function of cells from a primary culture is expected to resemble that of in vivo cells (46). The cell isolation procedure is performed in a class II biosafety cabinet to minimize contamination. There is no standard protocol for the isolation of human ASCs. Generally, adipose tissue is enzymatically digested, centrifuged and filtered (see Figure 1). Factors including heterogeneity between patients, tissue depot, concentration and collagenase type, centrifugation and media formulations may result in variability in the yield and in vitro characteristics of the cells. These factors may affect marker expression, differentiation capability and therapeutic potential.

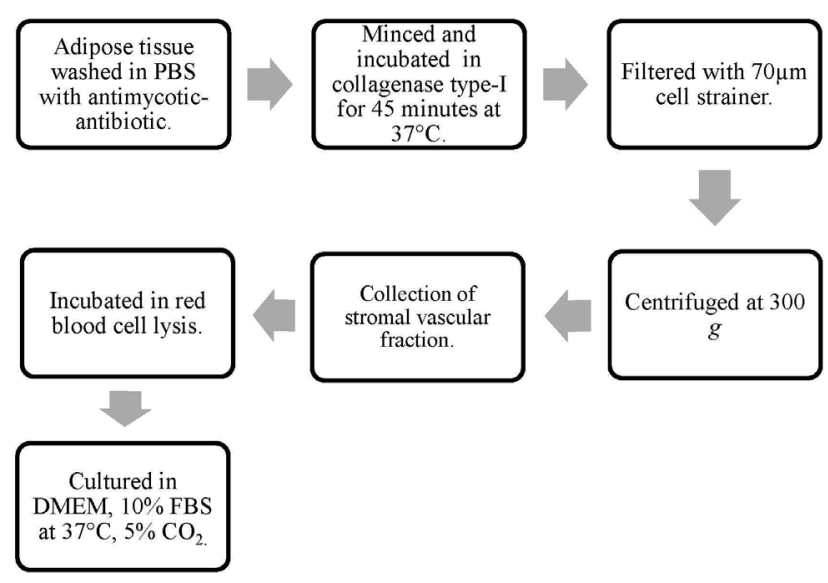

Figure 1: Isolation of ADSCs from human adipose tissue. Abbreviations: PBS: phosphate buffered saline, DMEM: Dulbecco's modified eagle medium, FBS: fetal bovine serum.

One of the ways to isolate cells from tissue is by enzymatic disaggregation. Tissue is washed with phosphate-buffered saline to remove debris and blood. It is then minced and incubated in collagenase with continuous rotation. Collagenase is widely used as an enzyme to help disperse the collagenase bundles that are present in the extracellular matrix and thus dissociate cells from tissue. Many types of digestion buffer have been used to digest the tissue, including collagenase type I (18) and collagenase with trypsin (23). The optimal collagenase concentration and digestion time are $0.2 \%$ and 1 hour, respectively (47). The combination of collagenase with trypsin can shorten the time of incubation from 3 hours to 20 minutes (23). Trypsin is used to dissociate the cells. After incubation, the activity of collagenase and trypsin can be neutralized with growth medium containing serum. Collagenase is less aggressive than trypsin (48). The presence of erythrocytes can reduce ASCs adherence and proliferation (49). Therefore, erythrocyte cross-contamination can be overcome by lysing the red blood cells in lysis buffer. However, erythrocytes are also non-adherent to plastic, allowing primarily ASCs to attach.

The cells are centrifuged at $180 \mathrm{~g}$ for 5 minutes and filtered through a 70- $\mu \mathrm{m}$ cell strainer to obtain a single cell suspension and remove the undigested tissue. Centrifugation is not a precise cell separation technique; however, it concentrates the cells and removes fractions of cells based on density. Two measurements of centrifugal force are used: rpm (revolutions per minute) and $g$ (relative centrifugal force). The same centrifugal force may correspond to different rpm values among researchers if they have different radii of centrifugation. Therefore, specific gravity is used for standardization. Centrifugation of adipose tissue at more than $3000 \mathrm{~g}$ significantly damaged the adipose-derived stem cells, and the number of ASCs remained unchanged at $1200 \mathrm{~g}$ (50). Another finding suggested $1126 \mathrm{~g}$ as the optimal centrifugal force in comparison to $12,519 \mathrm{~g}$ and $4507 \mathrm{~g}$, which resulted in more viable ASCs (51). To date, there is no extensive research on the relationship of various centrifugal forces on the yield of ASCs.

ASCs in the culture appear spindle-shaped or fibroblastlike $(17,23,52)$. When $70-80 \%$ confluence is reached, the cultured cells need to be further propagated in additional vessels, a procedure called sub-culture. Cells can be detached from the culture flask by incubating the cells in dissociating agents, such as trypsin, for $3-5$ minutes at $37^{\circ} \mathrm{C}$. Culture flasks can be tapped to assist with cell detachment. Detached cells usually float and exhibit a round shape in the culture medium.

A simple and fast method to quantify viable cells utilizes the trypan blue exclusion assay. Viable cells with intact membranes do not take up the blue dye; thus, dead cells with blue color can be distinguished from viable cells. The expansion of cells in vitro requires growth medium. Growth medium provides necessary nutrients, growth factors and hormones, and it regulates the culture $\mathrm{pH}$ and osmotic pressure. This medium is a combination of basal media and $10-20 \%$ of serum. Basal media is a media that contains nutrients such as amino acids, vitamins, inorganic salts and a carbon source, such as glucose. The most frequently used basal media for ASC culture are Dulbecco's modified Eagle medium (DMEM) (35, 53-57), DMEM/F12 (58-62) and alpha-modified Eagle medium ( $\alpha$-MEM) (63). The expansion of ASCs in $\alpha-M E M$ is significantly better than the expansion in DMEM, DMEM/F12, F12 and LP02 (commercial media free from animal product) when all are supplemented with $10 \%$ serum (64). This parameter 
is evaluated based on the differentiation capacity of ASCs rather than the immunophenotype of the ASCs (64). Laboratory-made media composed of basal media, several growth factors such as basic fibroblast growth factor (bFGF) and epidermal growth factor (EGF), and serum have preserved the stemness of ASCs, as measured by their proliferation and expression of stemness transcriptional markers (49). However, human MSC stemness from bone marrow is better preserved in DMEM than in Iscove's modified Dulbecco's medium (IMDM) (65). High calcium medium can cause cell differentiation. Low calcium medium can accelerate proliferation and prolong their lifespan (66).

ASC stemness should be preserved in both in vitro and in vivo situations for optimal effects in regenerative medicine. The most common serum used is animal-derived, such as fetal bovine serum and fetal calf serum. Sera from animals may cause contamination and are expensive. Therefore, researchers are looking into new alternative formulations of media, such as serum-free media or animal-free sera (67-69). In addition, we can avoid transmission of diseases derived from animals if ASCs are employed clinically in humans. Similar results are obtained when porcine-derived trypsin is compared with animal protein-free products based on yield, viability and immunophenotype of the human ASCs (70). There is also a similar result for in vitro and in vivo proliferation and differentiation of human skeletal-derived MSCs when cultured in human serum and fetal bovine serum (71). Another study states that ASCs cultured in human allogeneic serum and fetal bovine serum have a similar surface marker phenotype but differ in gene expression after differentiation (72). Artificial serum substitute induces more profound cellular physiological changes in comparison to ASCs grown in fetal calf serum, pretested fetal calf serum or human allogeneic serum (73). Despite the fact that animal-free serum such as human serum may be a great alternative, mass production of serum from healthy humans may be needed for long term ASC culture.

The site of tissue harvesting may influence the concentration and function of human ASCs. Lipoaspirates from the inner thigh and lower abdomen may have a higher concentration of MSCs than lipoaspirates harvested from the upper abdomen, trochanteric region, knee, and flank (74). Different locations on the same individual may yield different amounts of stem cells. Subcutaneous adipose tissue from the hip has more stem cells than the subcutaneous space of the abdomen (75). This finding contradicts the results of a study, which found that subcutaneous adipose tissue abdomen yields more ASCs than adipose tissue from the hip or thigh region (22). In terms of gender, the abdomen has the highest cell yield in males compared to the knees and back region, whereas there is no significant relationship between the collection site and cell yield in females (47). The osteogenic differentiation capability of ASCs from superficial and deep fat and the dependence on gender and age have been examined. ASCs from the superficial layer of fat from males differentiate into osteocytes faster than those from the deep layer, while there is no significant differences of osteogenic properties of both depot in female (76). In humans, there are no data supporting which type of adipose tissue has greater plasticity. Nevertheless, subcutaneous structural WAT sites that have weak collagenic bundles and are rich in stem cells are preferable to sources of deposit WAT and fibrous WAT (12). However, in mice, inguinal WAT has shown greater differentiation potential than BAT (77).

There is inconsistency among researchers regarding the influence of age and body mass index (BMI) on the proliferation of ASCs. ASCs from younger donors have a higher proliferation rate than those from older donors (78). However, a study has found no significant relationship between age and the proliferation rate of ASCs (79). There is no significant correlation between the frequency of adipose-derived stem cells and BMI (22), and there are no statistical correlations between age and $\mathrm{BMI}$ and the proliferation and yield of ASCs $(47,80)$. Different isolation methods, culture conditions and sites from which adipose tissue is taken may cause variation between studies.

In addition to the manual isolation of cells, there is an automated device called the Celution ${ }^{\mathrm{TM}}$ system that is designed to wash, digest and concentrate cells from adipose tissue. These isolated cells comprise a heterogeneous population that contains ASCs, endothelial cells and vascular smooth muscle cells. The cells isolated by a Celution ${ }^{\mathrm{TM}}$ system possess equivalent expression results for certain markers and equivalent differentiation ability to cells isolated by the manual method (81). In comparison to enzymatic isolation, the mechanical isolation of cells from lipoaspirates can reduce the cost of collagenase and time of digestion while maintaining their antigen expression and differentiation capacity (82). ASCs can also be derived from mature adipocytes by dedifferentiating them into lipid-free fibroblast-like cells $(83,84)$.

There are heterogeneous populations of cells that may adhere to the plastic surfaces of a culture flask after the enzymatic aggregation of tissue. The isolation of ASCs by immuno-magnetic beads prior to culturing can reduce cross-contamination with unwanted cells. The cells are incubated with beads that are conjugated with MSCassociated antibodies, such as CD 105, CD 90 and CD73. The magnetically labeled cells are retained within the magnetic field in the column and collected by flushing out the cells after removing the column from the magnetic field. The isolated cells can be cultured, and the attached beads are biodegradable. The immuno-magnetic bead separation of cells after collagenase digestion of adipose tissue results in several subpopulations that share typical marker expression (85). Three different isolation methods have been studied to reduce the heterogeneity of cultures; these methods are based on adherence on plastic, washing after one hour of cell seeding and immuno-magnetic isolation by specific markers. Washing after one hour of seeding significantly reduces the heterogeneity of the cell population and increases stem cell marker expression. A more homogenous population is achieved when loosely attached cells are washed away after one hour of seeding instead of changing the medium after 24 hours or more (86). 
Many protocols have been developed for the cryopreservation of ASCs. Cryopreservation requires a medium and a cryoprotectant. Fetal bovine serum prevents the viability loss of ASCs, and cryoprotective agents such as dimethylsulphoxide prevent cell death due to extreme temperature. ASCs can be cryopreserved for at least 6 months while maintaining their proliferation capability and surface marker profiles (87). Storage of liposuction samples for 24 hours at $4^{\circ} \mathrm{C}$ before processing the samples could increase the yield of stem cells (88).

\section{Immunophenotyping of ASCs}

In addition to adhering to plastic, stem cells must express specific surface antigens or proteins. The expression of specific antigen is crucial for clinical applications. Immunophenotyping of ASCs can be performed at various stages of culture (freshly isolated cells, early passages and late passages) and using various experimental methods (western blot, flow cytometry, immunofluorescence and immunocytochemistry). These methods offer either quantitative or qualitative expression of antigen. The depot of adipose tissue and type of sample (liposuction or excised adipose tissue) may influence the percentage of expression.

The Mesenchymal and Tissue Stem Cell Committee of the International Society for Cellular Therapy has proposed that more than $95 \%$ of the MSC population must express CD105, CD73 and CD90, as measured by flow cytometry. Additionally, these cells must lack expression (less than $2 \%$ positive) of CD45, CD34, CD 14 or CD11b, CD79a or CD19 and HLA class II (8). Positive and negative markers of ASCS are summarized according to the publication in which they appear (see Table 1).

Table 1: $\quad$ Positive and negative markers of ASCs, as reviewed:

\begin{tabular}{|c|c|}
\hline Positive & Negative/ Very Low \\
\hline $\operatorname{CD} 29(23,89,90,109,110)$ & $\operatorname{CD} 31(22,89,90,109,111)$ \\
\hline $\operatorname{CD} 44(23,90,109-111)$ & $\operatorname{CD} 45(22,23,89,90,109,111,112)$ \\
\hline $\operatorname{CD} 49 d(89,111)$ & CD34 $(23,90,91,109,111)$ \\
\hline $\operatorname{CD73}(89,90,109,110,112)$ & $\operatorname{CD} 106(22,109,111)$ \\
\hline $\operatorname{CD} 90(22,89,109-112)$ & HLA-II (109) \\
\hline CD105 $(22,23,89,90,109-113)$ & CD14 (109) \\
\hline $\operatorname{CD} 13(23,111,113)$ & CD44 (110) \\
\hline $\operatorname{CD} 166(22,23)$ & HLA-DR $(22,23,90,91)$ \\
\hline CD34 (22) & CD146 (22) \\
\hline HLA-ABC (22) & CD117 (91) \\
\hline CD71 (111) & \\
\hline
\end{tabular}

ASCs express surface markers such as integrins (CD29, CD49d), surface enzymes (CD73), extracellular matrix proteins (CD90 and CD105) and hyaluronate (CD44). In contrast, ASCs do not express hematopoietic progenitor cell marker (CD34), vascular cell adhesion molecule (CD106), monocyte differentiation antigen (CD14), endothelial cell adhesion molecule (CD31) and leukocyte common antigen (CD45). Katz et al. demonstrated that ASCs strongly express proteins related to cell adhesion, matrix proteins, growth factors and receptors, and proteases (58).

Most papers report that cultured ASCs exhibit significantly increased expression of positive markers in the subsequent cultures (subcultures) (89-91). High expression of CD105, which is an MSC marker, has indicated that these cells can be applied to stem cells therapy (89). In contrast, decreased expression of CD105 is related to the differentiation of MSC into osteogenic, adipogenic, chondrogenic and epithelial pathways (92). CD34, CD31, CD45 are highly expressed in freshly isolated cells, and most reports claim that their expression decreases with successive cultures. This finding implies that the population of ASCs becomes more homogenous with increasing sub-cultures. Positive expression may be correlated with heterogeneous cell population in freshly isolated cells (SVF), which are composed of ASCs, endothelial cells and vascular smooth muscle cells (81). While CD34+ ASCs have greater proliferation potential, CD34- ASCs exhibit greater ability to differentiate into mesenchymal lineages (93).

ASCs share the same profile of antigen expression as MSCs from bone marrow: CD29, CD13, CD44, CD 73, CD90, CD105 and CD166 $(59,94)$. The differences between ASCs and bone-marrow-derived MSC are the expression of CD106 (only expressed by bone-marrow-derived MSCs) and CD 49d (only expressed by ASCs) (95). Mature fibroblasts in connective tissue also express CD29, CD44, CD90, CD105 and are negative for CD34, CD117 and CD146 (96).

\section{Current clinical applications of ASCs}

The multipotential nature and secretion ability of ASCs encourage to their clinical application. Here, we discuss the application of ASCs to soft tissue reconstruction and augmentation, wound management (radiation injury) and orthopedic clinical applications.

\section{Soft tissue reconstruction and augmentation}

Adipose tissue has been utilized as an autologous tissue for soft tissue augmentation to repair congenital and acquired tissue damage. To survive, the graft must be vascularized and supplied with adequate nutrients and cell sources. Differentiated adipocytes from autologous ASCs were injected into the depressed scars of thirty-one patients, and long-term follow up in seven patients revealed that the volume of the graft was maintained for up 12 weeks compared to conventional fat transfer (97). The injection of ASCs alone was not sufficient to support adipogenesis; thus, adipocytes differentiated from ASCs enhanced adipose tissue formation (98). Another novel method to enhance survival of graft was achieved by combining autologous fat with fat containing a stromal vascular fraction. This technique is known as cell-assisted lipotransfer (CAL), 
which improves the survival rate of the graft and enhances angiogenesis in breast tissue augmentation and facial lipoatrophy $(99,100)$. ASC differentiation to adipocytes and vascular endothelial cells, secretion of growth factors and replication are important events that contribute to adipose tissue regeneration, angiogenesis and graft survival in CAL treatment (101). ASCs can be employed allogeneically because they possess immunosuppressive properties (lack of HLA-DR expression) $(102,103)$.

\section{Wound management (Radiation injury)}

Autologous lipoaspirate administered into lesions caused by radiation therapy treatment of oncologic patients improved the regeneration of tissue and the restoration of function. ASCs have been reported to actively participate in the regeneration and neovascularization of tissue (104).

In Japan, autologous non-cultured ASCs isolated by the Celution $^{\mathrm{TM}}$ System were used as a treatment for local chronic injuries caused by radiation. The treated injuries were caused by nuclear power plant accidents or radiation therapy. In the conventional method of treatment, multiple surgical procedures must be performed before the wound can heal. Autologous non-cultured ASCs applied to the wound area with artificial dermis and sprayed with growth factors resulted in improved tissue regeneration after 1.5 years (105).

\section{Orthopaedic}

Calvarial fracture in children was treated with autologous ASCs in autologous fibrin glue. After three months, the fractures showed ossification of the defect (106). Another study also employed autologous ASCs isolated according to GMP guidelines and expanded in vitro using autologous serum. These cells were combined with beta-tricalcium phosphate and scaffold construct seeded into the rectus abdominal muscle of patients with hard palate defects. Bone formation and vascularization of tissue occurred after 8 months (107). ASCs were induced to osteocytes and implanted at surgically produced defects in the palatal bones of rats to examine the ability of differentiated ASCs to treat bone defects. The group treated with ASCs and scaffold exhibited significant bone regeneration (108). ASCs offer alternative treatments to traditional bone grafting, and this method is suitable when there is a shortage of autogenous bone, particularly in the cases of children and donor-site morbidity.

\section{Conclusions and future directions}

ASCs possess significant potential in regenerative medicine. ASCs have captured researchers' attention because, within 10 years, the investigation of their applications has progressed from bench to bedside. Numerous methods of isolation and culture conditions have been manipulated to obtain optimum ASCs expansion. Further study and standardization of the isolation protocol and antigen profiles would substantially enhance clinical advancement. ASCs have antioxidant, anti-aging, anti-inflammatory and wound healing properties, as demonstrated in vitro and in preclinical models. Cell therapy using ASCs can reduce morbidity and the healthcare cost burden to sustain their development in countries without compromising safety issues.

Basic science knowledge of ASCs can be expanded by further investigation of ASC biology. These findings may facilitate researchers' understanding of the in vitro behavior of these cells, which can translate into clinical applications. ASCs production potentially benefitting regenerative medicine should be performed in accordance with the provided code of practice. Further clinical trials are necessary to continue validation of the applications of ASCs and improve their clinical outcome.

*For literature searching, authors key in "adipose-derived stem cells", "mesenchymal stem cells", "adipose tissue", "characterization of adipose-derived stem cells", "isolation of adipose-derived stem cells", "clinical application of adipose-derived stem cells" in PubMed portal and Science Direct.

\section{Acknowledgement}

The related work on the adipose-derived stem cells presented in this paper is supported by Research University Grant of Universiti Sains Malaysia (No. 1001/PPSP/813058).

\section{References}

1. Hipp J, Atala A.Sources of stem cells for regenerative medicine, Stem Cell Rev 2008;4 (1):3-11.

2. Gimble JM.Adipose tissue-derived therapeutics, Expert Opin Biol Ther 2003;3(5):705-713.

3. Lakshmipathy $U$, Verfaillie C. Stem cell plasticity, Blood Rev 2005;19(1):29-38.

4. De Ugarte DA, Morizono K, Elbarbary A, et al. Comparison of multi-lineage cells from human adipose tissue and bone marrow, Cells Tissues Organs 2003; 174(3):101-109.

5. Thomson JA, Itskovitz-Eldor J, Shapiro SS, et al. Embryonic stem cell lines derived from human blastocysts, Science 1998; 28(5391):1145-1147.

6. Takahashi K, Tanabe K, Ohnuki M, et al.Induction of pluripotent stem cells from adult human fibroblasts by defined factors, Cell 2007;131 (5):861-872.

7. Tuan RS, Boland G, Tuli R. Adult mesenchymal stem cells and cell-based tissue engineering, Arthritis Res Ther 2003; 5(1):32-45.

8. Dominici $\mathrm{M}$, Le Blanc $\mathrm{K}$, Mueller I, et al. Minimal criteria for defining multipotent mesenchymal stromal cells. The International Society for Cellular Therapy position statement, Cytotherapy 2006; 8(4):315-317. 
9. Wang P, Mariman E, Renes J, et al. The secretory function of adipocytes in the physiology of white adipose tissue, J Cell Physiol 2008; 216(1):3-13.

10. Nedergaard J, Bengtsson T, Cannon B. Unexpected evidence for active brown adipose tissue in adult humans, Am J Physiol Endocrinol Metab 2007; 293(2):E444-452.

11. Ahima RS. Adipose tissue as an endocrine organ, Obesity (Silver Spring) 2006; 14 Suppl 5:242S-249S.

12. Sbarbati A, Accorsi D, Benati D, et al. Subcutaneous adipose tissue classification, Eur J Histochem 2010; 54(4):e48.

13. Lin CS, Xin ZC, Deng CH, et al. Defining adipose tissuederived stem cells in tissue and in culture, Histol Histopathol 2010; 25(6):807-815.

14. Spalding KL, Arner E, Westermark PO, et al. Dynamics of fat cell turnover in humans, Nature 2008; 453(7196):783-787.

15. Lin G, Garcia M, Ning $H$, et al. Defining stem and progenitor cells within adipose tissue, Stem Cells Dev 2008; 17(6):1053-1063.

16. Maumus M, Peyrafitte JA, D’Angelo $\mathrm{R}$, et al. Native human adipose stromal cells: localization, morphology and phenotype, Int J Obes (Lond) 2011; 35(9):1141-1153.

17. Zuk PA, Zhu M, Mizuno $\mathrm{H}$, et al. Multilineage cells from human adipose tissue: implications for cellbased therapies, Tissue Eng 2001; 7(2):211-228.

18. Bunnell BA, Flaat M, Gagliardi C, et al. Adipose-derived stem cells: isolation, expansion and differentiation, Methods 2008; 45(2):115-120.

19. Brown SA, Levi B, Lequeux C, et al. Basic science review on adipose tissue for clinicians, Plast Reconstr Surg 2010; 126(6):1936-1946

20. Traktuev DO, Merfeld-Clauss S, Li J, et al. A population of multipotent CD34-positive adipose stromal cells share pericyte and mesenchymal surface markers, reside in a periendothelial location, and stabilize endothelial networks, Circ Res 2008; 102(1):77-85.

21. Crisan M, Yap S, Casteilla L, et al. A perivascular origin for mesenchymal stem cells in multiple human organs, Cell Stem Cell 2008; 3(3):301-313.

22. Jurgens WJ, Oedayrajsingh-Varma MJ, Helder MN, et al. Effect of tissue-harvesting site on yield of stem cells derived from adipose tissue: implications for cell-based therapies, Cell Tissue Res 2008; 332(3):415-426.

23. Zhu Y, Liu T, Song K, et al. Adipose-derived stem cell: a better stem cell than BMSC, Cell Biochem Funct 2008; 26(6):664-675.

24. Cao Y, Sun Z, Liao L, et al. Human adipose tissuederived stem cells differentiate into endothelial cells in vitro and improve postnatal neovascularization in vivo, Biochem Biophys Res Commun 2005; 332(2):370-379.

25. Rodriguez AM, Elabd C, Delteil F, et al. Adipocyte differentiation of multipotent cells established from human adipose tissue, Biochem Biophys Res Commun 2004; 315 (2):255-263.
26. Hattori H, Sato M, Masuoka K, et al. Osteogenic potential of human adipose tissue-derived stromal cells as an alternative stem cell source, Cells Tissues Organs 2004; 178(1):2-12.

27. Guilak F, Awad HA, Fermor B, et al. Adipose-derived adult stem cells for cartilage tissue engineering, Biorheology 2004; 41(3-4):389-399.

28. Kim HJ, Im GI. Chondrogenic differentiation of adipose tissue-derived mesenchymal stem cells: greater doses of growth factor are necessary, J Orthop Res 2009; 27(5):612-619.

29. Harris LJ, Abdollahi H, Zhang P, et al .Differentiation of adult stem cells into smooth muscle for vascular tissue engineering, J Surg Res 2011; 168(2):306-314.

30. Rodriguez LV, Alfonso Z, Zhang R, et al. Clonogenic multipotent stem cells in human adipose tissue differentiate into functional smooth muscle cells, Proc Natl Acad Sci U S A 2006; 103(32):12167-12172.

31. Wosnitza M, Hemmrich K, Groger A, et al. Plasticity of human adipose stem cells to perform adipogenic and endothelial differentiation, Differentiation 2007; 75(1):12-23.

32. Safford KM, Hicok KC, Safford SD, et al. Neurogenic differentiation of murine and human adipose-derived stromal cells, Biochem Biophys Res Commun 2002; 294(2):371-379.

33. Brzoska M, Geiger H, Gauer S, et al. Epithelial differentiation of human adipose tissue-derived adult stem cells, Biochem Biophys Res Commun 2005; 330(1):142-150.

34. Baer PC, Doring C, Hansmann ML, et al. New insights into epithelial differentiation of human adiposederived stem cells, J Tissue Eng Regen Med 2013; 7(4):271-278.

35. Timper K, Seboek D, Eberhardt M, et al. Human adipose tissue-derived mesenchymal stem cells differentiate into insulin, somatostatin, and glucagon expressing cells, Biochem Biophys Res Commun 2006; 341(4):1135-1140.

36. Seo MJ, Suh SY, Bae YC, et al. Differentiation of human adipose stromal cells into hepatic lineage in vitro and in vivo, Biochem Biophys Res Commun 2005; 328(1):258-264.

37. Rehman J, Traktuev D, Li J, et al. Secretion of angiogenic and antiapoptotic factors by human adipose stromal cells, Circulation 2004; 109(10):1292-1298.

38. Kim WS, Park BS, Sung JH, et al. Wound healing effect of adipose-derived stem cells: a critical role of secretory factors on human dermal fibroblasts, $J$ Dermatol Sci 2007; 48(1):15-24.

39. Kim WS, Park SH, Ahn SJ, et al. Whitening effect of adipose-derived stem cells: a critical role of TGF-beta 1, Biol Pharm Bull 2008; 31(4):606-610.

40. Kim WS, Park BS, Kim HK, et al. Evidence supporting antioxidant action of adipose-derived stem cells: protection of human dermal fibroblasts from oxidative stress, J Dermatol Sci 2008; 49(2):133-142.

41. Park BS, Kim WS, Choi JS, et al. Hair growth stimulated by conditioned medium of adipose-derived stem cells 
is enhanced by hypoxia: evidence of increased growth factor secretion, Biomed Res 2010; 31(1):27-34.

42. Kim JH, Jung M, Kim HS, et al. Adipose-derived stem cells as a new therapeutic modality for ageing skin, Exp Dermatol 2011; 20(5):383-387.

43. Uysal AC, Mizuno $H$, Tobita $M$, et al. The effect of adipose-derived stem cells on ischemia-reperfusion injury: immunohistochemical and ultrastructural evaluation, Plast Reconstr Surg 2009; 124(3):804-815.

44. Lu F, Mizuno H, Uysal CA, et al .Improved viability of random pattern skin flaps through the use of adipose-derived stem cells, Plast Reconstr Surg 2008; 121(1):50-58.

45. Freshney RI, Obradovic B, Grayson, et al. Principles of Tissue Culture and Bioreactor Design. In: Lanza L, et al., eds. Principles of Tissue Engineering:UK: Elsevier Academic Press; 2007:156-157.

46. Mather JP, Roberts PE. Introduction.Introduction to cell and tissue culture: theory and technique. New York: Plenum Press;1998: 1-8.

47. Faustini $M$, Bucco M, Chlapanidas T, et al. Nonexpanded mesenchymal stem cells for regenerative medicine: yield in stromal vascular fraction from adipose tissues, Tissue Eng Part CMethods 2010; 16(6):15151521.

48. Manjula. S. Animal Biotechnology, Cell Culture Technique and Cell Lines. New D e I h i : Laxmi Publications (P) LTD;2007: 25.

49. Baer PC, Griesche N, Luttmann W, et al. Human adipose-derived mesenchymal stem cells in vitro: evaluation of an optimal expansion medium preserving stemness, Cytotherapy 2010; 12(1):96106.

50. Kurita M, Matsumoto D, Shigeura T, et al. Influences of centrifugation on cells and tissues in liposuction aspirates: optimized centrifugation for lipotransfer and cell isolation, Plast Reconstr Surg 2008; 121(3):1033-1041; discussion 1042-1033.

51. Galie M, Pignatti M, Scambi I, et al. Comparison of different centrifugation protocols for the best yield of adipose-derived stromal cells from lipoaspirates, Plast Reconstr Surg 2008; 122(6):233e-234e.

52. Lin Y, Liu L, Li Z, et al. Pluripotency potential of human adipose-derived stem cells marked with exogenous green fluorescent protein, Mol Cell Biochem 2006; 291(1-2):1-10.

53. Baer PC, Schubert R, Bereiter-Hahn J, et al. Expression of a functional epidermal growth factor receptor on human adipose-derived mesenchymal stem cells and its signaling mechanism, Eur J Cell Biol. 2009; 88(5): 273-283.

54. Zhu Y, Liu T, Song K, et al. Ex vivo expansion of adipose tissue-derived stem cells in spinner flasks, Biotechnol J 2009; 4(8):1198-1209.

55. Francis MP, Sachs PC, Elmore LW, et al. Isolating adipose-derived mesenchymal stem cells from lipoaspirate blood and saline fraction, Organogenesis 2010; 6(1):11-14.
56. Kim WS, Park BS, Park SH, et al Antiwrinkle effect of adipose-derived stem cell: Activation of dermal fibroblast by secretory factors, J Dermatol Sci 2009; 53(2):96-102.

57. Ling Z, Yuan G, Lijun K, et al. Compatibility of chitosangelatin films with adipose tissue derived stromal cells, TSINGHUA SCIENCE AND TECHNOLOGY 2006; 11(4):421-426.

58. Katz AJ, Tholpady A, Tholpady SS, et al. Cell surface and transcriptional characterization of human adipose-derived adherent stromal (hADAS) cells, Stem Cells 2005; 23(3):412-423.

59. Pachon-Pena G, Yu G, Tucker A, et al. Stromal stem cells from adipose tissue and bone marrow of age-matched female donors display distinct immunophenotypic profiles, J Cell Physiol 2011; 226(3):843-851.

60. Flynn L, Prestwich GD, Semple JL, et al. Adipose tissue engineering with naturally derived scaffolds and adipose-derived stem cells, Biomaterials 2007; 28(26):3834-3842.

61. Park IS, Han M, Rhie JW, et al. The correlation between human adipose-derived stem cells differentiation and cell adhesion mechanism, Biomaterials 2009; 30(36):6835-6843.

62. Trottier V, Marceau-Fortier G, Germain L, et al .IFATS collection: Using human adipose-derived stem/stromal cells for the production of new skin substitutes, Stem Cells 2008; 26(10):2713-2723.

63. Jun ES, Lee $\mathrm{TH}, \mathrm{ChoHH}$, et al. Expression of telomerase extends longevity and enhances differentiation in human adipose tissue-derived stromal cells, Cell Physiol Biochem 2004; 14(4-6):261-268.

64. Lund P, Pilgaard L, Duroux $M$, et al. Effect of growth media and serum replacements on the proliferation and differentiation of adipose-derived stem cells, Cytotherapy 2009; 11(2):189-197.

65. Pieri L, UrbaniS, MazzantiB, etal.Human mesenchymal stromal cells preserve their stem features better when cultured in the Dulbecco's modified Eagle medium, Cytotherapy 2011; 13(5):539-548.

66. Lin TM, Tsai JL, Lin SD, et al. Accelerated growth and prolonged lifespan of adipose tissue-derived human mesenchymal stem cells in a medium using reduced calcium and antioxidants, Stem Cells Dev 2005; 14(1):92-102.

67. Dromard C, Bourin P, Andre M, et al. Human adipose derived stroma/stem cells grow in serum-free medium as floating spheres, Exp Cell Res 2011; 317(6):770-780.

68. Parker $A$, Shang $H$, Khurgel $M$, et al. Low serum and serum-free culture of multipotential human adipose stem cells, Cytotherapy 2007; 9(7):637-646.

69. Lindroos B, Boucher S, Chase L, et al. Serum-free, xeno-free culture media maintain the proliferation rate and multipotentiality of adipose stem cells in vitro, Cytotherapy 2009; 11(7) 958-972.

70. Carvalho PP, Wu X, Yu G, et al. Use of animal proteinfree products for passaging adherent human adipose- 
derived stromal/stem cells, Cytotherapy 2011; 13(5):594-597.

71. Aldahmash A, Haack-Sorensen M, Al-Nbaheen M, et al. Human serum is as efficient as fetal bovine serum in supporting proliferation and differentiation of human multipotent stromal (mesenchymal) stem cells in vitro and in vivo, Stem Cell Rev 2011; 7(4):860868.

72. Lindroos B, Aho KL, Kuokkanen $\mathrm{H}$, et al. Differential gene expression in adipose stem cells cultured in allogeneic human serum versus fetal bovine serum, Tissue Eng Part A 2010; 16(7):2281-2294.

73. Tunaitis V, Borutinskaite V, Navakauskiene R, et al. Effects of different sera on adipose tissue-derived mesenchymal stromal cells, J Tissue Eng Regen Med 2011; 5(9):733-746.

74. Padoin AV, Braga-Silva J, Martins $P$, et al. Sources of processed lipoaspirate cells: influence of donor site on cell concentration, Plast Reconstr Surg 2008; 122(2):614-618.

75. Fraser J, Wulur I, Alfonso Z, et al. Differences in stem and progenitor cell yield in different subcutaneous adipose tissue depots, Cytotherapy 2007; 9(5):459467.

76. Aksu AE, Rubin JP, Dudas JR, et al. Role of gender and anatomical region on induction of osteogenic differentiation of human adipose-derived stem cells, Ann Plast Surg 2008; 60(3):306-322.

77. Prunet-Marcassus B, Cousin B, Caton D, et al. From heterogeneity to plasticity in adipose tissues: sitespecific differences, Exp Cell Res 2006; 312(6):727736.

78. Schipper BM, Marra KG, Zhang W, et al. Regional anatomic and age effects on cell function of human adipose-derived stem cells, Ann Plast Surg 2008; 60(5):538-544.

79. Zhu M, Kohan E, Bradley J, et al. The effect of age on osteogenic, adipogenic and proliferative potential of female adipose-derived stem cells, J Tissue Eng Regen Med 2009; 3(4):290-301.

80. Mojallal A, Lequeux C, Shipkov C, et al. Influence of age and body mass index on the yield and proliferation capacity of adipose-derived stem cells, Aesthetic Plast Surg 2011; 35(6):1097-1105.

81. Lin K, Matsubara Y, Masuda Y, et al. Characterization of adipose tissue-derived cells isolated with the Celution system, Cytotherapy 2008; 10(4):417-426.

82. Baptista LS, do Amaral RJ, Carias RB, et al. An alternative method for the isolation of mesenchymal stromal cells derived from lipoaspirate samples, Cytotherapy 2009; 11(6):706-715.

83. Matsumoto T, Kano K, Kondo D, et al. Mature adipocyte-derived dedifferentiated fat cells exhibit multilineage potential, J Cell Physiol 2008; 215(1):210222.

84. Shen JF, Sugawara A, Yamashita J, et al. Dedifferentiated fat cells: an alternative source of adult multipotent cells from the adipose tissues, Int J Oral Sci 2011; $3(3): 117-124$.
85. Rada T, Reis RL, Gomes ME. Distinct stem cells subpopulations isolated from human adipose tissue exhibit different chondrogenic and osteogenic differentiation potential, Stem Cell Rev 2011; 7(1):6476.

86. Griesche N, Luttmann W, Luttmann A, et al. A simple modification of the separation method reduces heterogeneity of adipose-derived stem cells, Cells Tissues Organs 2010; 192(2):106-115.

87. Gonda K, Shigeura T, Sato T, et al. Preserved proliferative capacity and multipotency of human adipose-derived stem cells after longterm cryopreservation, Plast Reconstr Surg 2008; 121(2):401-410.

88. Eom YW, Lee JE, Yang MS, et al. Rapid isolation of adipose tissue-derived stem cells by the storage of lipoaspirates, Yonsei Med J 2011; 52(6):999-1007.

89. Yoshimura K, Shigeura T, Matsumoto D, et al. Characterization of freshly isolated and cultured cells derived from the fatty and fluid portions of liposuction aspirates, J Cell Physiol 2006; 208(1):6476.

90. Yang XF, He X, He J, et al. High efficient isolation and systematic identification of human adipose-derived mesenchymal stem cells, J Biomed Sci 2011;18:59

91. Varma MJ, Breuls RG, Schouten TE, et al. Phenotypical and functional characterization of freshly isolated adipose tissue-derived stem cells, Stem Cells Dev 2007; 16(1):91-104.

92. Jin HJ, Park SK, Oh W, et al. Down-regulation of CD105 is associated with multi-lineage differentiation in human umbilical cord blood-derived mesenchymal stem cells, Biochem Biophys Res Commun 2009; 381(4):676-681.

93. Suga $H$, Matsumoto $D$, Eto $H$, et al. Functional implications of CD34 expression in human adiposederived stem/progenitor cells, Stem Cells Dev 2009; 18(8):1201-1210.

94. Bailey AM, Kapur S, Katz AJ. Characterization of adipose-derived stem cells: an update, Curr Stem Cell Res Ther 2010; 5(2):95-102.

95. Zuk PA, Zhu M, Ashjian P, et al. Human adipose tissue is a source of multipotent stem cells, Mol Biol Cell 2002; 13(12):4279-4295.

96. Blasi A, Martino C, Balducci L, et al. Dermal fibroblasts display similar phenotypic and differentiation capacity to fat-derived mesenchymal stem cells, but differ in anti-inflammatory and angiogenic potential, Vasc Cell 2011; 3(1):5.

97. Kim M, Kim I, Lee SK, et al .Clinical trial of autologous differentiated adipocytes from stem cells derived from human adipose tissue, Dermatol Surg 2011; 37(6):750-759.

98. Cho SW, Kim I, Kim SH, et al. Enhancement of adipose tissue formation by implantation of adipogenicdifferentiated preadipocytes, Biochem Biophys Res Commun 2006; 345(2):588-594.

99. Yoshimura K, Asano $\mathrm{Y}$, Aoi N, et al. Progenitorenriched adipose tissue transplantation as rescue 
for breast implant complications, Breast J 2010; 16(2):169-175

100. Yoshimura K, Sato K, Aoi N, et al. Cell-assisted lipotransfer for cosmetic breast augmentation: supportive use of adipose-derived stem/stromal cells, Aesthetic Plast Surg 2008; 32(1):48-55; discussion 56-47.

101. Yoshimura K, Suga H, Eto H. Adipose-derived stem/ progenitor cells: roles in adipose tissue remodeling and potential use for soft tissue augmentation, Regen Med 2009; 4(2):265-273.

102. Puissant B, Barreau C, Bourin P, et al. Immunomodulatory effect of human adipose tissuederived adult stem cells: comparison with bone marrow mesenchymal stem cells, Br J Haematol 2005; 129(1):118-129.

103. Yanez R, Lamana ML, Garcia-Castro J, et al. Adipose tissue-derived mesenchymal stem cells have in vivo immunosuppressive properties applicable for the control of the graft-versus-host disease, Stem Cells 2006; 24(11):2582-2591.

104. Rigotti G, Marchi A, Galie M, et al. Clinical treatment of radiotherapy tissue damage by lipoaspirate transplant: a healing process mediated by adiposederived adult stem cells, Plast Reconstr Surg 2007; 119(5):1409-1422; discussion 1423-1404.

105. Akita S, Akino K, Hirano A, et al. Noncultured autologous adipose-derived stem cells therapy for chronic radiation injury, Stem Cells Int 2010:532704.

106. Lendeckel S, Jodicke A, Christophis $P$, et al. Autologous stem cells (adipose) and fibrin glue used to treat widespread traumatic calvarial defects: case report, J Craniomaxillofac Surg 2004; 32(6):370-373.

107. Mesimaki K, Lindroos B, Tornwall J, et al. Novel maxillary reconstruction with ectopic bone formation by GMP adipose stem cells, Int J Oral Maxillofac Surg 2009; 38(3):201-209.

108. Conejero JA, Lee JA, Parrett BM, et al. Repair of palatal bone defects using osteogenically differentiated fat-derived stem cells, Plast Reconstr Surg 2006; 117(3):857-863.

109. Baglioni S, Francalanci $M$, Squecco $R$, et al. Characterization of human adult stem-cell populations isolated from visceral and subcutaneous adipose tissue, FASEB J 2009; 23(10):3494-3505.

110. Yu G, WuX, Dietrich MA, et al. Yield and characterization of subcutaneous human adipose-derived stem cells by flow cytometric and adipogenic mRNA analyzes, Cytotherapy 2010; 12(4):538-546.

111. Folgiero V, Migliano $\mathrm{E}$, Tedesco $\mathrm{M}$, et al. Purification and characterization of adipose-derived stem cells from patients with lipoaspirate transplant, Cell Transplant 2010; 19(10):1225-1235.

112. Sathishkumar S, Mohanashankar P, P. CB. Cell surface protein expression of stem cells from human adipose tissue at early passage with reference to mesenchymal stem cell phenotype, Int. J. Med. Med Sci 2011; 3:129-134.

113. Potdar PD, Sutar JP. Establishment and molecular characterization of mesenchymal stem cell lines derived from human visceral \& subcutaneous adipose tissues, Journal of Stem Cells \& Regenerative Medicine 2010; 6(1):26-35. 